\title{
ALIMENTAÇÃO DO BEBÊ DE BAIXO PESO NO DOMICÍlIO: ENFRENTAMENTOS DA FAMÍLIA E DESAFIOS PARA A ENFERMAGEM
}

\author{
Feeding the baby with low birth weight at home: family coping and challenges for \\ nursing care \\ Alimentación del bebé de baj o peso en casa: enfrentamientos de la familia y desafíos \\ para la enfermería
}

Sandra Teixeira de Araújo Pacheco ${ }^{1}$

Ivone Evangelista Cabral ${ }^{2}$

\begin{abstract}
RESUMO
Bebês de baixo peso ao nascer apresentam demandas de cuidados na alimentação decorrentes das exigências metabólicas no primeiro ano de vida, desafiando as famílias no confronto entre as recomendações dos profissionais e as práticas culturais. Para desvelar e articular a prática sociocultural dos familiares na alimentação deste bebê, aplicou-se o método criativo-sensível, no domicílio de seis famílias, no período de abril de 2008 a março de 2009. Segundo a análise crítica do discurso, as famílias desvelaram os contextos hospitalar, domiciliar e societal de alimentação do bebê, ideologicamente articulados com a prática social. Enquanto a ordem do discurso hospitalar favoreceu o aleitamento materno exclusivo, as ordens local e societal desvelaram as práticas culturais da amamentação e alimentação, articuladas ou não com discurso profissional. 0 discurso dos profissionais de saúde influenciou o início da amamentação exclusiva, mas pouco contribuiu na sua manutenção. A inclusão da família nas intervenções contribui para a produção de novos sentidos na alimentação deste bebê.
\end{abstract}

Palavras-chave: Enfermagem Pediátrica. Aleitamento Materno. Recém-nascido de Baixo Peso. Família. Cultura

\begin{abstract}
Low weight babies on birth present demands of care in the feeding resulting from the metabolic needs in the first year of life, challenging the families in the confrontation between the professionals' recommendations and the cultural practices. In order to reveal and articulate the socio-cultural practice of family in this baby' s feeding, it applied the creative-sensitive method, at six families' domiciles in the period of March 2008 to April 2009. According to the critical analyzes of the speech, the families revealed the hospital context, domiciliary and societal contexts of baby's feeding, ideologically articulated with the social practice. While the hospital discourse order favored the exclusive maternal breastfeeding, the local and societal order revealed the breastfeeding and feeding cultural practices, articulated or not with professional point of view. The health professionals' $s$ discourse influenced the beginning of the exclusive breastfeeding, but few contributed in theirs maintenance. The family's inclusion in the interventions contributes to the production of new senses in this baby's feeding.
\end{abstract}

Keywords: Pediatric nursing. Breast Feeding. Infant, Low Birth Weight. Family. Culture.

\section{Resumen}

Bebés de bajo peso al nacer presentan demandas de cuidados en la alimentación decurrentes de las exigencias metabólicas en el primer año de vida, desafiando las familias en el confronto entre las recomendaciones de los profesionales y las prácticas culturales. Para desvelar y articular la práctica sociocultural de los familiares en la alimentación de este bebé, se aplicó el método creativo-sensible, en el domicilio de seis familias, en el periodo de marzo de 2008 a abril de 2009. Según el análisis crítico del discurso, las familias desvelaron los contextos hospitalario, domiciliario y societario de alimentación del bebé, de forma ideológica, articulada con la práctica social. Mientras la orden del discurso hospitalario favoreció la alimentación materna exclusiva, las ordenes local y societaria desvelaron las prácticas culturales de la lactancia materna y la alimentación, articuladas o no con discurso profesional. El discurso de los profesionales de salud influenció el inicio del amamantar exclusivo, pero poco contribuyó en su manutención. La inclusión de la familia en las intervenciones contribuye para la producción de nuevos sentidos en la alimentación de este bebé.

Palabras clave: Enfermería pediátrica. Lactancia Materna. Recién Nacido de Bajo Peso. Familia. Cultura.

'Doutora em Enfermagem. Professora Adjunta do Departamento de Enfermagem Materno-Infantil da Faculdade de Enfermagem da Universidade do Estado do Rio de Janeiro. Rio de Janeiro-RJ. Brasil. E-mail: stapacheco@yahoo.com.br. ,'Doutora em Enfermagem. Professora Associada do Departamento de Enfermagem Materno-Infantil. Escola de Enfermagem Anna Nery. Pesquisadora do CNPQ e do NUPESC/EEAN. Rio de Janeiro-RJ. Brasil. E-mail: icabral44@hotmail.com. 


\section{INTRODUÇÃO}

A Organização Mundial da Saúde e o Ministério da Saúde recomendam a amamentação exclusiva para todas as crianças até os seis meses de idade e a introdução de alimentos complementares a partir de então, de forma lenta e gradual. No tocante à prática alimentar do bebê de baixo peso (BBP), tanto a primeira como a segunda recomendação representam fatores de proteção à sua saúde. Entretanto, estudos ${ }^{1-5} \mathrm{com}$ enfoque sociocultural, associam gênero, comportamento, valores, crenças do grupo cultural e familiar com o aleitamento predominante e a introdução de outros alimentos precocemente.

Embora no hospital a clínica tenha apontado que 0 bebê em referência apresenta demandas nutricionais próprias, com risco de hipoglicemia e perda acentuada de peso, o leite materno tem atendido as demandas e corrigido os distúrbios metabólicos. Em casa, o manejo da alimentação do bebê de baixo peso é uma tarefa desafiadora para a família, e independentemente de o tipo de alimento ser o leite materno ou outro, haverá sempre dificuldades no ajuste entre a alimentação e as suas demandas metabólicas.

0 recém-nascido de baixo peso ao nascer apresenta, além do fator peso, peculiaridades próprias da regulação da temperatura corporal, gerando a necessidade de monitoramento mais restrito do crescimento e desenvolvimento e do estado de saúde, devido ao maior risco de exposição ao adoecimento. ${ }^{6}$ Do ponto de vista clínico, esses fatores situam o recém-nascido com tais necessidades no grupo de crianças com necessidades especiais de saúde (CRIANES). Do mesmo modo que as CRIANES, ele apresenta limitações no seu estilo de vida e nas suas funções normais para a idade, com maiores demandas de cuidados contínuos, de natureza temporária ou permanente, que as demais crianças em geral. ${ }^{7}$

Por apresentar condições especiais de saúde com demanda de cuidados habituais modificados relacionados à nutrição, a família do bebê de baixo peso precisa aprender a manejar sua alimentação, e não apenas a mãe. Portanto, o manejo do cuidado habitual modificado na alimentação do bebê de baixo peso apresenta-se como um desafio para a enfermagem de cuidado domiciliar, particularmente no encontro com os saberes e práticas locais modeladas pelo contexto social e cultural da família. Nesse sentido, traçamos como objetivos: desvelar a prática social dos familiares no manejo da alimentação do recém-nascido de baixo peso e interpretar os modos de articulação dessa prática social com as práticas culturais adotadas por essas famílias quando no domicílio.

\section{ABORDAGEM DE PESQUISA E O MÉTODO DE INVESTIGAÇÃO}

Após a aprovação do projeto pelo Comitê de Ética em Pesquisa (Protocolo 2013 CEP/HUPE), a pesquisa qualitativa foi desenvolvida segundo o método criativo sensível ${ }^{8}$, cujas bases fundam-se na tríade: discussão de grupo, dinâmica de criatividade e sensibilidade (DCS) e observação participante. No conjunto de dinâmicas já validadas por outros pesquisadores, elegemos duas: Mapa Falante e Corpo Saber. ${ }^{8}$ Com a dinâmica do Mapa Falante, aproximamo-nos dos locais na comunidade e das pessoas que contribuíram/participaram na alimentação do bebê de baixo peso. Na dinâmica Corpo Saber, buscamos conhecer que ações os familiares empreendiam no manejo da alimentação do bebê de baixo peso, bem como os espaços sociais nos quais desenvolviam suas práticas e as crenças que orientavam a realização desse cuidado.

Após consentimento da chefia do ambulatório pediátrico de um hospital universitário, buscamos identificar, por meio da leitura de prontuários indicados pela equipe, as crianças que preenchiam os critérios de inclusão do estudo. Assim, foram incluídas as mães cujas crianças apresentaram registro de peso ao nascer entre 1.500 a $2.499 \mathrm{~g}$, baixo risco ao nascer, alta da unidade neonatal e/ou alojamento conjunto amamentando exclusivamente e idade limite de um ano no momento da pesquisa. Em seguida, abordamos a pessoa que acompanhava a criança previamente selecionada (responsável legal e/ou mãe) na consulta médica de puericultura.

A partir desse encontro, conversamos com a responsável pela criança sobre a pesquisa, os objetivos e o local onde a pesquisa seria desenvolvida. Naquela oportunidade, falamos sobre a formação dos grupos cujos participantes deveriam ser indicados por elas, por serem pessoas de suas relações, participantes dos cuidados a criança, e que desejassem participar como voluntários da pesquisa. Formaram-se seis grupos de familiares cuidadores que receberam a denominação fictícia de: "família de Guilherme", "família de Uli", "família de Pedro", "família de João", "família de Maria Vitória" e "família de Raphael", totalizando 25 participantes. A todos explicamos o Termo de Consentimento Livre e Esclarecido antes de sua assinatura. As falas dos familiares foram gravadas em fitacassete e, após a realização das DCS, foram transcritas na íntegra. A pesquisa foi desenvolvida no período de abril de 2008 a março de 2009.

Por evidenciarmos elementos da macroestrutura social marcadas na constituição do discurso desses familiares, optamos pela vertente da Análise Crítica de Discurso (ACD) de Fairclough ${ }^{9}$ para desenvolver a análise do material empírico.

0 modelo da ACD de Fairclough aponta que qualquer evento discursivo pode ser analisado a partir de três dimensões. A primeira caracteriza-se pela análise textual e linguística. Nesta fase, 0 analista do discurso preocupa-se em analisar o texto, buscando evidenciar as características do vocabulário, da gramática, da coesão e da estrutura textual. Na segunda dimensão, o analista leva em conta a prática discursiva do sujeito como algo produzido, apreendido e compartilhado consensualmente entre as pessoas. Esta análise está centrada nos conceitos de intertextualidade manifesta e interdiscursividade. 
A inter textualidade manifesta está relacionada com a presença explicita de outros textos específicos no texto sob análise. Já a interdiscursividade caracteriza-se pela presença, no discurso, de fragmentos discursivos que foram ditos antes, em algum lugar, por outra pessoa. Esta é constituída por meio de uma combinação de elementos de ordens de discurso.

No nível de ordens de discurso, as relações entre as práticas discursivas e os limites dessas práticas em uma instituição ou sociedade são modificadas segundo as direções seguidas pela mudança social e a hierarquia de cada discurso na esfera social.

A análise do discurso como reflexo da prática social centra-se nos conceitos de ideologia e hegemonia. 0 discurso como prática ideológica constitui, naturaliza, mantém e transforma os significados do mundo de posições diversas nas relações de poder. Já o conceito de hegemonia possibilita analisar a prática social à qual pertence o discurso em termos de relações de poder, isto é, se essas relações de poder reproduzem, reestruturam ou desafiam as hegemonias existentes.

\section{RESULTADOS E DISCUSSÃO}

As práticas sociais dos familiares cuidadores no manejo da alimentação do bebê de baixo peso foram alicerçadas em três contextos de aprendizagem: hospitalar, domiciliar e societal. Tais contextos apontaram para uma estrutura de formação ideológica hierarquicamente assentada em três ordens de discursos: institucional, local e societal.

\section{Contexto Hospitalar}

Leite materno - o primeiro alimento do bebê de baixo peso e as barreiras no contexto hospitalar

As narrativas dos familiares cuidadores apontaram um conjunto de dificuldades consideradas no escopo desse texto como barreiras com configuração diferenciada em função do contexto em que a mulher se inseriu no curso do manejo da alimentação do bebê de baixo peso.

Por barreira, neste texto, consideramos qualquer obstáculo ou impedimento que pudesse interferir na habilidade do profissional de saúde ou do cliente de diversidade cultural em atingir completamente os objetivos da promoção da saúde e prevenção de doenças. ${ }^{10}$

A prática social da amamentação foi marcada por obstáculos de natureza subjetiva e objetiva, passíveis de superações quando havia intervenções dos profissionais pontuais, contínuas e resolutivas.

A importância da amamentação, que, para mim, no começo foi um pouquinho difícil. Eu tentava dar de mamar e ele [o bebê] não pegava o bico do peito. Aí, veio uma enfermeira... E ela me ajudou. (Sra. Monica, mãe de Guilherme).

Porque machucava. Porque quando eu dava o peito para ele, ele não pegava. Aĺ, as doutoras do hospital tinham que ir lá pra me ajudar. (Sra. Natália, mãe de Pedro Henrique)

Ela (Natalia) não tinha bico, ainda estava formando. Aí, elas (as doutoras) ajudavam a pegar o peito. Porque a boquinha dele (Pedro) ainda era pequenininha, porque ele (Pedro) não estava acostumado [...]. Aí, elas ajudavam (Sra.Greice, avó materna de Pedro Henrique)

Porque o leite não sai assim tão fácil. A criança não se adéqua tão fácil assim. (Sra. Viviane, mãe de João Gabriel).

Tomando o hospital como referência, os familiares apontaram os obstáculos de natureza subjetiva, na etapa inicial da prática social da amamentação. Destacaram aquele momento como difícil, ruim, que machucava, não sendo, portanto, um momento simples de se lidar, pois a criança não se adequava tão facilmente à amamentação. No conjunto de barreiras objetivas, destacaram: o bebê não pegava o bico do peito, não tinha bico do peito, a boquinha do bebê era pequena e o leite não sai assim tão fácil.

Entretanto, os profissionais de saúde desempenharam um papel essencial na superação dessas barreiras iniciais. Os depoimentos apontaram que o suporte dos profissionais materializou-se em uma relação terapêutica de ajuda e ensino, cujo foco principal foi a superação das barreiras subjetivas e objetivas relacionadas à prática social da amamentação.

0 oferecimento do leite materno pelo copo

Outro aprendizado emergente nos discursos dos familiares foi o oferecimento do leite materno pelo copo.

Então, no quarto, eu dei o leite (materno), a enfermeira veio e me ensinou a dar o leite. Eu disse: "Ai, meu Deus! Eu nunca fiz isso, dar o leite no copinho.". Achei isso um absurdo, estranha. [...] Ah! Pelo meu conhecimento, eu nunca tinha visto isso, entendeu? [...]. Então, eu achei [...] a um nenenzinho desse tamanho assim...

Ai, meu Deus do Céu!

A enfermeira disse: "Ai, mãe, tenha paciência que ele (o bebê) vai tomar".

Aí, eu disse: "Ele [o bebê] está parecendo um gatinho lambendo o leite!". 
Aí, ela disse: "É um gatinho mesmo!". Etudo isso me deixou apavorada. Porque, se ele [o bebê] fosse assim com o peso normal, assim de mais de três quilos, tudo bem. (Sra. Val, avó materna de João Gabriel).

Na filosofia de cuidado da Iniciativa Hospital Amigo da Criança, para promover e apoiar a prática social do aleitamento materno exclusivo, o profissional de saúde ensina os familiares a oferecer o leite materno pela técnica do copo, cujo objetivo é evitar o contato precoce do bebê com outros bicos que não 0 peito materno.

Os ensinamentos da enfermeira sobre a técnica de alimentação com o leite materno pelo copinhoforam integrados ao saber intergeracional das avós dos bebês de baixo peso, mesmo com estranhamentos e absurdos da parte delas.

Embora o saber profissional tenha se infiltrado no saber das famílias com o objetivo de minimizar risco e potencializar benefícios, a utilização do copo no manejo da alimentação do bebê, independentemente da idade gestacional e da adequação de peso, tem sido questionada por alguns estudiosos. Algumas desvantagens da alimentação com o copo vem sendo destacado por estes pesquisadores: ${ }^{11} 0$ bebê costuma babar; pode haver formação de bolhas no leite, e o cuidador pode despejar o leite diretamente na boca da criança, ficando esta suscetível a engasgos e aspirações.

Nesse sentido, a preocupação e o medo dos familiares com o risco de engasgo, broncoaspiração e morte do bebê evidenciam a fragilidade desse instrumental no manejo do aleitamento materno pelo familiar.

\section{Contexto Domiciliar}

A amamentação e a oferta do leite materno e as barreiras no contexto domiciliar

No domićlio, a amamentação e a oferta de leite materno ao bebê de baixo peso foram explicadas pelas dificuldades das mães, dos bebês e dos familiares nos primeiros dias em casa e do mesmo modo que no contexto hospitalar: foi traduzida como um momento difícil para a mãe, o bebê e os familiares, sem, na maioria das vezes, contar com o mesmo suporte profissional de quando hospitalizado.

É. Porque, no começo, foi muito difícil. [...] Porque eu não tinha bico. Ela [Uli] não pegava direito [o bico do peito]. Ficou muito machucado [referindo ao bico do peito]. Ficou ferido o meu peito. [...] Foi muito ruim. [...] Porque ela [Uli] estava chorando muito e meu leite tinha ainda que tirar (ordenhar o peito) tinha que fazer massagem [no peito], para depois que tirar dar [o peito] para a Uli. (Sra. Lara, mãe de Uli)
Porque ele não conseguia pegar bem o peito, não conseguia mamar. Meu peito doía muito, ele chorava muito [...]. Aí, minha mãe e minha sogra diziam que o peito não estava alimentando (Sra. Fabíola, mãe de Raphael).

Achava que era fome. A gente achava que o meu peito era muito grande para ele [o bebê]. Então, ele (o bebê) não mamava o que tinha que mamar, entendeu? Ela (a avó) achava que eu o sufocava (o bebê). Ela [a avó] achava que o meu peito estava matando ele [o bebê] sufocado. (Srra. Viviane, mãe de João Gabriel).

Para a mãe, foi ruim dar o peito porque não tinha bico, machucava, doía, ficava ferido, tinha que tirar o leite e fazer massagem nele. Para o bebê, ele não pegava o peito, não conseguia mamar, não mamava o que tinha que mamar. Para a família, no campo das percepções destacaram-se crenças relacionadas às características morfológicas do bebê (a boca era pequena demais) e da mama materna (o peito era muito grande para o bebê e o peito estava matando o bebê sufocado), além das propriedades nutritivas do leite materno (não alimentava o bebê).

A essas barreiras somam-se as de natureza social, destacadas pelos familiares de Maria Vitória e Guilherme.

Porque, umas noites dessas, que eu dormi aqui [casa de Maria Vitória], ela [o bebê] chorou a noite inteira e ninguém conseguia dormir de tanto que ela chorava. Essa casa tem dois quartos, é muito pequena... Impossivel de a gente não ouvir o choro dela (o bebê). [...] ela [o bebê] chorando, chorando, chorando, e a Núbia dando o peito; peito: e ela, chorava; peito: e chorava. (Sra. Patrícia, tia materna de Maria Vitória).

0 choro do bebê foi uma barreira social importante na amamentação noturna. Residir em uma casa de dois quartos levou todos os familiares a participarem da vida social da mãe que amamentava o filho, pois o choro contínuo do bebê foi fonte de distúrbio do sono da família: impossível não se ouvir o choro. Ninguém conseguia dormir. Naquela casa, coabitavam seis pessoas que, diariamente, desempenhavam atividade laboral ou estudantil e que, portanto, necessitavam de um sono noturno tranquilo para desenvolver as próprias atividades no dia seguinte. Consequentemente, a prática social da amamentação noturna foi estendida a todo o grupo familiar, não sendo privativa apenas da mãe e do bebê.

Ao desvelar as barreiras de natureza subjetiva, objetiva e social, encontramos os modos de superação dos familiares no manejo da alimentação do bebê de baixo peso. 
Aí, ela [Uli] estava chorando muito, e, aí, a gente deu [a mamadeira]. (Sra. Lara, mãe de Uli)

Mas também foi só aquele dia [momento] [...].

Na família de Uli, para superar as barreiras diante do choro do bebê e da dificuldade da saída do leite materno, os familiares introduziram, momentaneamente, a fórmula láctea na alimentação da criança. Assim, ao oferecer a fórmula láctea à criança de forma transitória e pontual (foi só naquele momento do desespero), os familiares levaram em consideração elementos contextuais para decidir pela introdução de outro leite (fórmula láctea) na alimentação do bebê.

Teve hora de ela [Lara] querer mesmo parar de amamentar e dar mamadeira. (Sra. Geni, avó paterna de Uli)

É. Se não fosse pela gente mesmo, ela [Lara] tinha parado [de amamentar]. (Sra. Paloma, tia materna de Uli)

0 meu pai era o que mais falava. Tem que dar o peito tem que dar [o peito]. (Sra. Lara, mãe de Uli)

Ele [o pai] que ajudou a fazer a massagem. Era o que tinha mais jeito, mais jeito que a gente. Fazia massagem, desempredava, ficava apertando e, aí, saia tudinho [referindo-se ao leite]. Ele [o pai] era mais paciente que a gente (Sra. Paloma, tia materna de Uli).

No movimento discursivo dos familiares de Uli, evidencia-se que o apoio e a participação dos familiares foram pilares fundamentais para que Lara, a mãe do bebê de baixo peso Uli, mantivesse, após esse evento único, apenas o leite materno como a fonte alimentar de filha. Nos discursos, foi desvelado o desejo materno de Lara de interromper a amamentação e iniciar a alimentação por mamadeira.

No contexto domiciliar, o apoio familiar foi decisivo para que a mãe do bebê não desistisse da amamentação exclusiva.

Como você superou? (A pesquisadora).

Aí, papai pegava no colo. Ele me ajudou bastante. (Sra. Monica, mãe de Guilherme)

Na família de Guilherme, o pai participou ativamente na superação da barreira relacionada à alteração no ciclo de sono e vigília do bebê. Foi ele quem ajudou a pegar o bebê no colo nas noites em que a criança não queria dormir.

A respeito da participação masculina no manejo das práticas alimentares no domicilio, um estudo realizado com mulheres em Hong Kong acerca dos fatores que contribuíram para a decisão das mulheres em continuar amamentando, mostrou a participação do marido como fator fundamental. Para elas, o encorajamento e apoio do marido foram importantes para que continuassem a amamentar exclusivamente. Esses achados são relevantes, pois apontam uma mudança de comportamento e de valor no que tange ao papel e às funções atribuídas ao homem ao longo de nossa história.

Você contou com a ajuda de alguém para superar isso? (sobre o incentivo dos familiares acerca da introdução de fórmula láctea na alimentação do bebê de baixo peso) (A pesquisadora).

Eu levei ele [o bebê] láno posto. Porque a consulta da Márcia [Pediatra do Guilherme estava marcada de dois em dois meses. A pediatra delas, que acompanha as meninas desde que elas nasceram ela (pediatra) disse que o peso dele estava normal. 0 peso dele estava bom. Aí, eu continuei amamentando [no peito]. (Sra. Monica, mãe de Guilherme).

Diante das mais variadas barreiras da prática social da amamentação, apenas a família de Guilherme buscou o suporte profissional de saúde. A mãe de Guilherme encontrou nesse suporte a intervenção resolutiva que assegurou a manutenção da amamentação. A avaliação do peso do bebê pela pediatra foi ressignificada pela mãe como fator positivo, além de ser a força motriz para continuar amamentando até os três meses de idade.

Ela mandou comprar o Nan [fórmula láctea]. Só depois que minha mãe comprou o leite, e ela [o bebê] está tomando o leite [fórmula láctea], ela está dormindo direitinho e não está chorando; aí, com certeza, era a comida, a alimentação. Ela não estava se alimentando com o peito. (Sra. Patrícia, tia materna de Maria Vitória)

A gente vendo aquele desespero [de amamentar o filho] todo dela [mãe do bebê], a gente falava para ela dar mamadeira [fórmula láctea], como a mãe dela também falava [...] Então era a orientação das duas (Sra Inah, avó paterna de Raphael).

Os familiares de Maria Vitória e Raphael superaram a barreira relacionada à crença de que o leite materno não era suficiente na alimentação do bebê de baixo peso; então, eles intervieram comprando, dando e indicando a introdução da fórmula láctea. Na família de Maria Vitória, a avó materna foi a pessoa que mandou comprar e dar fórmula láctea (Nan), 0 que levou o bebê a dormir e a não chorar mais. Já na segunda família, as avós maternas, diante do desespero da mãe na 
amamentação do filho, indicaram e introduziram a fórmula láctea como modo de transpor essa barreira.

Sabe-se que o oferecimento de fórmula láctea pode comprometer o sistema gastrointestinal do bebê e a capacidade dele de metabolizar esses componentes. ${ }^{13}$ Além disso, no campo da vulnerabilidade social, os gastos com a compra da lata de leite (fórmula látea) podem comprometer ainda mais o poder aquisitivo desses familiares, o que poderá levar, em curto prazo, à impossibilidade de aquisição e utilização de outros bens e serviços essenciais à manutenção do estado de saúde dessas crianças, prejudicando o orçamento para outras demandas de sobrevivência (alimentação, educação, lazer, moradia etc.) de outros membros da família, deixando-os ainda mais vulneráveis socialmente.

Mas... quando ela (a Vivian) saiu de lá (do hospital), (...) que ela veio para casa. Eu disse: "Aqui mesmo é comigo (rs). Comprei chuquinha. Tudo o que eu aprendi na minha vida com sobrinho, com as minhas irmãs, tudinho. [...] Era assim... Uma hora ela [a Viviane] colocava no peito. Quando ela(a Viviane) estava cansada ou quando ele [o bebê] mesmo não queria chupar, sugar, eu dizia: "vamos tirar esse leite [do peito] e colocar na chuquinha" e ele [ o bebê] tomava. [...] Porque quando ele [o bebê] mamava no peito, ele ficava chorando depois e, com a chuquinha, ele [o bebê] dormia. (Sra. Val, avó materna de João Gabriel)

Na família de João Gabriel, o modo que os familiares encontraram para superar as barreiras relacionadas ao choro do bebê, ao cansaço e à fadiga da mãe foi oferecer ora a amamentação, ora o leite materno pela chuquinha. A avó materna de João Gabriel contribuiu com a superação da barreira da alimentação do bebê comprando e dando de presente uma chuquinha. 0 saber intergeracional da avó fomentou a prática social da alimentação com a chuca, cuja explicação assentavase no fato de que o bebê não só parava de chorar como também conseguia dormir.

0 bebê, ao receber o leite pela mamadeira/chuca, apresenta maior facilidade de sucção pelo fato de o leite fluir abundantemente desde a primeira sucção. Assim, a criança pode estranhar a demora do fluxo maior de leite quando amamentada no peito. 0 reflexo de ejeção do leite leva aproximadamente um minuto para ser desencadeado, e algumas crianças podem não tolerar essa espera, podendo levá-las ao choro. ${ }^{14}$

Nesse sentido, visualizam-se possibilidades de negociação do saber dos profissionais de saúde com o saber intergeracional da família na perspectiva de infiltrar ideologicamente o saber profissional no saber local das famílias no manejo da alimentação do bebê de baixo peso.
Mas não foi o que eu aprendi lá [no hospital], ou seja, que não precisava fazer aquilo [dar o Nan]. Mas, na angústia, na ansiedade, a gente acabou fazendo [dar o Nan]. (Sra. Viviane, Mãe de João Gabriel).

Viviane revelou que, apesar de ter aprendido no contexto hospitalar que não era para dar outro leite diferente do materno, não foi isso que ela fez quando no domicílio.

A introdução de fórmula láctea na alimentação aconteceu em momentos de angústia e de ansiedade vividos por ela e pelos familiares quando o bebê não conseguia mamar direito o peito e em que o leite não saía. Então, a superação dessas barreiras ocorreu com a oferta eventual (às vezes) de fórmula láctea para a criança.

Mas quando [...] ele [o bebê] ainda dava umas choradinhas, a gente não sabia da cólica e tudo... Aí, minha irmã, que teve o filho, disse: "não, esse negócio é uma bobeira, bota logo a chupeta nele." Aí, eu dei. Aí, ele [o bebê] acabou acostumando a usar chupeta. Mas eu não concordava porque eu achava que tudo [o que havia aprendido no hospital] tinha uma coerência, tanto que eu segui, tentei ao máximo. Mas, lógico que, quando a gente vem para o ambiente familiar, e as pessoas têm aquele conhecimento do povo, aquela história toda, a gente acaba caindo no conto do vigário. (Sra. Viviane, mãe de João Gabriel).

Outra prática social adotada pelos familiares de João Gabriel para a superação da barreira relacionada ao choro do bebê foi o uso da chupeta.

No que se refere ao uso da chupeta, partindo do pressuposto de que as chupetas podem ser obstáculo à amamentação bem sucedida, a Organização Mundial da Saúde, conjuntamente com a UNICEF, incluiu entre os Dez passos para o Sucesso da Amamentação o não uso de chupetas nas maternidades para crianças amamentadas. ${ }^{15}$

Indo ao encontro da norma estabelecida no Passo 9 dos Dez passos para o Sucesso da Amamentação (não dar bicos ar tificiais ou chupetas a lactentes amamentados ao peito), os profissionais de saúde ensinam às mães dos bebês que a chupeta não ensina a criança a sugar, e que o uso dela pode levá-la a posicionar a língua de forma errada, dificultando a sucção da mama materna.

Sendo assim, no encontro com os profissionais de saúde do contexto hospitalar, a mãe do bebê de baixo peso reconheceu que o aprendizado transmitido pelos profissionais de saúde sobre o uso da chupeta era adequado e pertinente, o que influenciou-a a não oferecê-la ao filho quando inserida naquele contexto. Entretanto, quando inserida 
no contexto familiar, o uso da chupeta foi ressignificado pela mãe como um recurso que ajudava a cessar o choro do filho.

Os familiares consideraram a chupeta como um recurso para minimizar o choro do bebê, o que levou a mãe a aliar-se a esses familiares e aos saberes intergeracionais com base no modelo explicativo construído no senso comum. Mesmo que a mãe tenha, socialmente, interagido com a política de cuidado da Iniciativa Hospital Amigo da Criança no contexto hospitalar, quando no domicilio, ela rompe com esse aprendizado, passando a oferecer a chupeta ao filho. Nesse sentido, o uso da chupeta também foi considerado por ela como capaz de tranquilizar o choro da criança, transformando-a ideologicamente em uma crença alicerçada no saber intergeracional. Além disso, a indicação dos familiares para o uso da chupeta contribuiu para reforçar o significado construído pela mãe de que a chupeta trouxe melhoria no comportamento do filho.

Achado semelhante foi encontrado em outro estudo, em que a mãe oferecia a chupeta ao filho na tentativa de moldar o comportamento dele ou de, pelo menos, aproximá-lo do ideal esperado. ${ }^{16}$

A introdução de chás na alimentação do bebê de baixo peso

Ela (Avó) mandava [...] dar chazinho de erva-doce também. [...] Erva-doce, eu também dei no começo. (Sra. Monica, mãe de Guilherme)

Por que você deu chazinho de erva-doce? (A pesquisadora)

Chazinho de erva doce, porque passava um pouquinho da cólica [risos] [...] A cólica melhora um pouco e a criança dorme. (Sra. Monica, mãe de Guilherme).

No movimento discursivo da mãe de Guilherme, a introdução de chá de erva-doce demarcou a própria prática social da alimentação, desfavorável à pratica social da amamentação.

A introdução do chá de erva-doce na alimentação das crianças foi uma medida de superação da barreira cólica abdominal do bebê.

Na interpretação da mãe de Guilherme, a introdução desse líquido ajudou a passar um pouquinho a cólica, e houve melhora do sono de seu filho.

Entretanto, as recomendações do Ministério da Saúde ${ }^{13}$ apontam que os chás devem ser evitados na alimentação da criança, pois há evidências de que o uso deles está associado ao desmame precoce e ao aumento da morbimortalidade infantil.

A utilização de chá pelos familiares apresenta em si mesmo um sinal de perigo para a saúde do bebê de baixo peso. Sabe-se que a utilização do chá de erva-doce como remédio para acalmar cólicas, induzir ao sono e acalmar as crianças, além de ser desnecessária e concorrer para a menor ingestão do leite materno, interfere também na absorção do ferro. ${ }^{17}$

Se, por um lado, a prática cultural do uso do chá pelos familiares apontou a possibilidade do comprometimento da saúde do bebê, por outro, evidenciou a necessidade de estabelecer-se um diálogo entre os profissionais de saúde e os familiares, buscando a negociação dessa crença cultural, mas não a negação dela.

\section{Contexto Societal}

Aprendendo sobre a prática social da amamentação e sobre o leite materno

O pessoal do posto é que ensinou como colocar ela [o bebê] para mamar no peito (Sra. Lara, mãe de Uli)

O povo [vizinhos, amigos] falava assim: "De não dar água para a criança, também falavam para dar só o leite do peito." (Sra. Viviane, mãe de João Gabriel).

No processo ensino-aprendizado sobre a amamentação como prática social de alimentação do bebê de baixo peso, das seis famílias que participaram das DCS, apenas as famílias de Uli e de João Gabriel destacaram o espaço social da comunidade como lócus de aprendizado dessa prática alimentar.

Esses familiares, representados pelas mães dos bebês de baixo peso, ressaltaram que receberam "ensinamentos" sobre o posicionamento do bebê para amamentar e de dar o leite do peito sem oferecer outros líquidos ao bebê.

Falando sobre o leite materno e a complementação com mamadeira

As pessoas falaram o quê, Monica? ( A pesquisadora)

Para complementar com mamadeira que o leite era fraco. [...] As pessoas (amigos, vizinhos) diziam: "É. Este leite não sustenta! [...] (Sra. Monica, mãe de Guilherme).

E o que as pessoas [vizinhos, amigos] falavam para você dar, quando ele estava chorando com fome? (A pesquisadora)

Falavam para parar de dar o peito e dar comida. (Sra. Natália, mãe de Pedro Henrique).

Uma das coisas que ela [a amiga] me falou foi: "Ah! Viviane, esse negócio de peito é um mito." (Sra. Viviane, mãe de João Gabriel) 
As pessoas [da rua] falavam que eu não estava dando o peito direito, falava que o leite não estava enchendo a criança. Que o leite não estava alimentando (Sra. Núbia, mãe de Maria Vitória).

A complementação do leite materno com mamadeira foi mediada no processo ensino-aprendizado desses familiares, cuja justificativa assentou-se na interpretação de o leite materno ser fraco ou inadequado para o bebê, na interrupção do peito e no oferecimento de comida ao bebê e no peito como prática alimentar associada a mito.

Tem a televisão, que fala da importância do leite materno, acho que é bom, que evita doença, já vem prontinho, não precisa coar, não precisa ferver, nada disso (Sra. Monica, mãe de Guilherme).

A televisão também, não é? Eles falam que tem que amamentar até seis meses, não precisa de água, de suco, de nada. Só o leite materno [...]. Você pode dar até os dois anos, mas o essencial é até seis meses, sem nada, semágua, sem nada. Depois é só o complemento. Até para a mulher também faz bem, não é? Para evitar câncer de mama, o útero volta para o lugar mais rápido, e é muito melhor para todo mundo (Sra. Paloma, tia materna de Uli).

As famílias de Guilherme e Uli incorporaram em seus enunciados as vozes da mídia televisiva nas próprias práticas sociais e discursivas sobre as vantagens do leite materno para a saúde da criança e da mulher. Nesse sentido, o interdiscurso revela que, no contexto societal, a televisão assumiu um lugar estratégico, não só como fonte de informação, mas também de incentivo à prática do aleitamento materno.

Em síntese, da prática discursiva dos familiares emergiram duas matrizes da prática social do manejo da alimentação do bebê de baixo peso: a prática social da amamentação exclusiva e a prática social da alimentação (introdução de outros alimentos diferentes do leite materno).

\section{CONSIDERAÇÕES FINAIS}

As práticas discursivas dos familiares indicaram os contextos hospitalar, domiciliar e societal como constituintes dos saberes e das práticas de alimentação do bebê de baixo peso. As vozes dos profissionais adquiriram sonoridade nas vozes dos familiares como resultado das interações sociais quando nas instituições hospitalares, ambulatoriais e nos serviços de saúde da comunidade. Além disso, esses familiares aprenderam, com a transmissão de saberes intergeracionais desde a quinta geração, com os homens e as mulheres mais experientes da família, com os vizinhos, com os amigos e com a mídia sobre como alimentar o bebê de baixo peso.
A prática social da amamentação no hospital foi marcada por obstáculos de natureza subjetiva e objetiva, cuja superação foi assegurada pelas intervenções pontuais, ininterruptas e clinicamente resolutivas dos profissionais. A relação terapêutica de ajuda focalizou tanto as barreiras subjetivas quanto as objetivas. Entre as subjetivas, destacaramse a iniciação da amamentação como um momento da vida difícil, ruim, dolorido, complexo, de inadequação do bebê ao processo interacional exigido pelo contato com a amamentação. A relação terapêutica pautou-se nos ensinamentos sobre a oferta do leite materno com o copo medida (copinho) que foram integrados ao saber intergeracional das avós e das mães dos BBP, como uma experiência inédita, absurda, estranha e apavorante para os familiares. 0 estranhamento ocorreu em função de, outrora, os familiares não terem visualizado, no domicilio, alguém dando leite materno a um bebê por um copo. 0 medo do familiar residia na possibilidade de o bebê de baixo peso broncoaspirar, portanto, a família questionava sobre a pertinência do uso desse recurso em casa.

A despeito de todo o poder do discurso dos profissionais de saúde na promoção e apoio à prática do aleitamento materno exclusivo, nem todas as mães dos bebês de baixo peso continuaram com o leite materno como a única fonte de alimento para o filho após a alta hospitalar. No domicilio, outros saberes e outras práticas familiares assumiram o lugar na alimentação do bebê de baixo peso. 0 poder do discurso de familiares pertencentes a diferentes gerações foram decisivos nesse processo de mudança de atitude. Os valores e as normas familiares foram mais fortes na tomada de decisão sobre como alimentar o filho do que a memória discursiva dos profissionais de saúde.

A perspectiva familiar da oferta de alimentos incluiu o leite materno ora como fonte de saciedade da fome e da sede do bebê, ora como insuficiente para atender às necessidades alimentares. A indisponibilidade de profissionais para ensinar, auxiliar e ajudá-las na superação das barreiras socioculturais da amamentação exclusiva no domicilio levou à introdução dos mais variados alimentos.

Quanto ao contexto societal, diferentes enunciações sobre o manejo da alimentação do BBP representaram a diversidade de vozes dos membros da sociedade e da mídia, indicando práticas sociais semelhantes àquelas do contexto domiciliar. 0 efeito ideológico que circula no espaço social assumiu um papel importante na ordem do discurso societal, ora ensinando a prática do aleitamento materno exclusivo como prática social no manejo da alimentação do BBP, ora indicando a fórmula láctea.

Os discursos veiculados na mídia, por sua vez, assumiram um papel importante na formação ideológica dos familiares acerca do aleitamento materno exclusivo como prática social de alimentação da criança nos primeiros seis meses de vida e de forma continuada até os dois anos de idade. 0 manejo da alimentação do bebê de baixo peso no contexto do domicílio 
e da comunidade foi constituído por questões socioculturais; portanto, faz-se necessário que a enfermagem, como uma prática social, articule o paradigma biomédico e o sociocultural na perspectiva da promoção da saúde do BBP.

0 desafio para a enfermagem no contexto domiciliar reside na necessidade de conhecer as práticas culturais de alimentação como ponto de partida para a negociação de novas práticas alimentares. No que tange à prática social da amamentação, é preciso problematizar com a mulher que está amamentando, e seus familiares, questões referentes a essa prática alimentar. Além disso, é necessário o desenvolvimento de ações educativas junto à gestante e à sua família, desde 0 início do pré-natal. É preciso também que o enfermeiro favoreça e estimule a presença daqueles membros da família, que a mulher considera importante, para o processo de aprendizado sobre como amamentar o bebê durante a permanência no contexto hospitalar; insira os familiares em atividades de grupos e em momentos de orientação, buscando valorizar a presença e as contribuições deles nas ações de promoção da saúde; possibilite a criação de espaços democráticos e participativos; e estabeleça uma aproximação com a realidade de vida do grupo familiar em que o BBP vive.

\section{REFERÊNCIAS}

1.Groleau D, Soulière M, Kirmayer L. Breastfeding and the cultural configuration of social space among vietnamese immigrant woman. Health \& Place. 2005; 12(4): 516-26.

2.McCann MF, Bender DE. Perceived insufficient milk as a barrier to optimal infant feeding: examples from Bolivia. J Biosoc Sci. 2006; 38(3):341-64

3.Kakute PN, Ngum J, Mitchell P, Kroll KA, Forgwei GW, Ngwang LK et al. Cultural barriers to exclusive breastfeeding by mothers in a rural area of Cameroon, Africa. J Midwifery \& Women's Health. 2005; 50(4): 324-28.

4.Poli LMC, Castro LMCP,Zagonel IPS. Prática do aleitamento materno: a cultura familiar na transferência de conhecimentos. Fam Saude Desenvol. 1999; 1(1/2): 33-8.

5.Nakano AMS, Reis MCG, Pereira MJB, Gomes FA. 0 espaço social das mulheres e a referencia para o cuidado na prática da amamentação. Rev Latino-am Enfermagem. 2007; 15 (2): 230-38.

6.Cabral IE, Moraes JRMM, Santos FF. 0 egresso da terapia intensiva neonatal de três instituições públicas e a demanda de cuidados especiais. Esc Anna Nery. 2003; 7(2): 211-18.

7.Neves ET, Cabral IE. A fragilidade clínica e a vulnerabilidade social das crianças com necessidades especiais de saúde. Rev Gaucha Enferm. 2008; 29 (2): 182-90.
8.Cabral, IE. 0 método criativo e sensível: alternativa de pesquisa na enfermagem. In: Gauthier JHM, Cabral IE, Santos I, Tavares CMM.Pesquisa em enfermagem: novas metodologias aplicadas. Rio de Janeiro: Guanabara Koogan; 1998. p. 177-208.

9.Fairclough N. Discurso e mudança social. Brasilia(DF): UNB; 2001.

10.Huff RM, Kline MV. Health promotion in the context of culture. In: Huff RM, Kline MV. Promotion health in multicultural populations: a handbook for practitioners. Sage Publications; 1998. p. 138-43.

11.Lima VP, Melo AM. 0 uso do copinho no alojamento canguru. Rev CEFAC. 2008; 10(1): 126-33.

12.Kong SKF, Lee DTF. Factors influencing decision to breastfeed. J Adv Nurs. 2004; 46(4): 369-79.

13. Ministério da Saúde (BR). Guia alimentar para crianças menores de 2 anos. Brasília (DF), 2002. (Série A. Normas e manuais Técnicos, 107)

14.Ministério da Saúde (BR). Secretaria de Atenção à Saúde. Departamento de Atenção Básica. Saúde da criança: nutrição infantil: aleitamento materno e alimentação complementar. Brasília (DF); 2009. (Caderno de Atenção Básica, 23)

15.Soares MEM, Giugliani ERJ, Braun ML, Salgado ACN, Oliveira AP, Aguiar PR. Uso da chupeta e sua relação com o desmame em população de crianças nascidas em Hospital Amigo da Criança. J Pediatr. 2003; 79(4): 309-16.

16.Sertório SC, Silva IA. As faces simbólicas e utilitárias da chupeta na visão das mães. Rev Saude Publica. 2005; 39(2): 156-62.

17.Parada CMGL, Carvalhaes MABL, Jamas MT. Práticas de alimentação complementar em crianças no primeiro ano de vida. Rev Latino-am Enfermagem. 2007; 15(2): 103-10. 